\title{
UASB - DIGITAL
}

Repositorio Institucional del Organismo Académico de la Comunidad Andina, CAN

El contenido de esta obra es una contribución del autor al repositorio digital de la Universidad Andina Simón Bolívar, Sede Ecuador, por tanto el autor tiene exclusiva responsabilidad sobre el mismo y no necesariamente refleja los puntos de vista de la UASB.

Este trabajo se almacena bajo una licencia de distribución no exclusiva otorgada por el autor al repositorio, y con licencia Creative Commons - Reconocimiento de créditos-No comercial-Sin obras derivadas 3.0 Ecuador

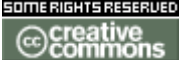

\section{The Ethics of Ethics Reviews in Global Health Research: Case Studies Applying a New Paradigm}

\author{
Annalee Yassi, Jaime Breilh, Shafik \\ Dharamsi, Karen Lockhart and Jerry \\ M. Spiegel
}




\section{The Ethics of Ethics Reviews in Global Health Research: Case Studies Applying a New Paradigm}

\section{Annalee Yassi, Jaime Breilh, Shafik Dharamsi, Karen Lockhart \& Jerry M. Spiegel}

Journal of Academic Ethics

ISSN 1570-1727

$\mathrm{J}$ Acad Ethics

DOI 10.1007/s10805-013-9182-y

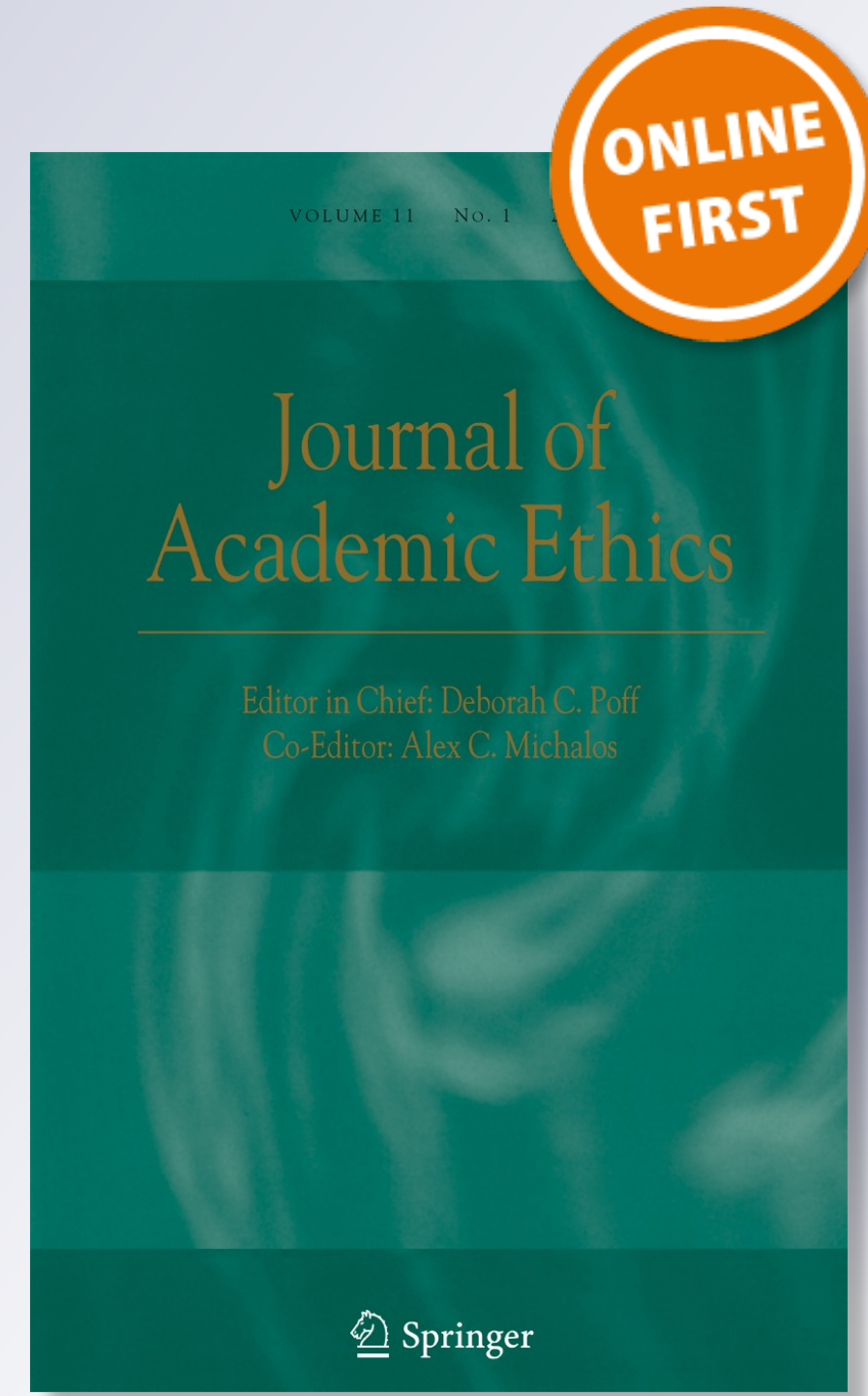

旬 Springer 
Your article is protected by copyright and all rights are held exclusively by Springer Science +Business Media Dordrecht. This e-offprint is for personal use only and shall not be selfarchived in electronic repositories. If you wish to self-archive your article, please use the accepted manuscript version for posting on your own website. You may further deposit the accepted manuscript version in any repository, provided it is only made publicly available 12 months after official publication or later and provided acknowledgement is given to the original source of publication and a link is inserted to the published article on Springer's website. The link must be accompanied by the following text: "The final publication is available at link.springer.com". 


\title{
The Ethics of Ethics Reviews in Global Health Research: Case Studies Applying a New Paradigm
}

\author{
Annalee Yassi • Jaime Breilh • Shafik Dharamsi • \\ Karen Lockhart • Jerry M. Spiegel
}

(C) Springer Science+Business Media Dordrecht 2013

\begin{abstract}
With increasing calls for global health research there is growing concern regarding the ethical challenges encountered by researchers from high-income countries (HICs) working in low or middle-income countries (LMICs). There is a dearth of literature on how to address these challenges in practice. In this article, we conduct a critical analysis of three case studies of research conducted in LMICs. We apply emerging ethical guidelines and principles specific to global health research and offer practical strategies that researchers ought to consider. We present case studies in which Canadian health professional students conducted a health promotion project in a community in Honduras; a research capacity-building program in South Africa, in which Canadian students also worked alongside LMIC partners; and a community-university partnered research capacity-building program in which Ecuadorean graduate students, some working alongside Canadian students, conducted community-based health research projects in Ecuadorean communities. We examine each case, identifying ethical issues that emerged and how new ethical paradigms being promoted could be concretely applied. We conclude that research ethics boards should focus not only on protecting individual integrity and human dignity in health studies but also on beneficence and non-maleficence at the community level, explicitly considering social justice issues and local capacity-building imperatives. We conclude that researchers from HICs interested in global health research must work with LMIC partners to implement collaborative processes for assuring ethical research
\end{abstract}

A. Yassi $\cdot$ K. Lockhart $(\bowtie) \cdot$ J. M. Spiegel

School of Population and Public Health (SPPH) in the Faculty of Medicine,

University of British Columbia, Vancouver, Canada

e-mail: annalee.yassi@ubc.ca

J. Breilh

Department of Health, University of Andina Simon Bolivar (UASB), Quito, Ecuador

e-mail: jaime.breilh@uasb.edu.ec

S. Dharamsi

Department of Family Practice in the Faculty of Medicine, University of British Columbia, Vancouver, Canada

e-mail: shafik.dharamsi@familymed.ubc.ca

S. Dharamsi · J. M. Spiegel

Liu Institute for Global Issues, University of British Columbia, Vancouver, Canada 
that respects local knowledge, cultural factors, the social determination of health, community participation and partnership, and making social accountability a paramount concern.

Keywords Global health research ethics $\cdot$ Low and middle-income countries · Ethical review

"People from all over the world come here to study our community. They do tests and ask us a lot of questions. They then go away and get their (titulos) degrees, and nothing improves for the community"

-Forewoman from the Wool Mill, Salinas de Guaranda, Ecuador

"To do research you have to ask about peoples' problems. When we asked the community about respiratory health and found that the stoves in the households contributed to respiratory problems, were we prepared to supply them with stoves? No!"

-Student from University of British Columbia (UBC), Canada

\section{Introduction}

With expanding activity in global health research, there is increasing concern over the range of ethical issues that can emerge, especially, although certainly not exclusively, when researchers from high-income-countries (HICs) actually conduct research in low and middle-income countries (LMICs) (Roth 2001; Lavery et al. 2010; Montgomery 1993). There are at least two important dimensions of this problem. The first dimension is the enormous ethical violations, when, to use the words of Davis: "the science of doubt promotion - the concerted and well-funded effort to identify, magnify and exaggerate doubts about what we could say that we know as a way of delaying actions to change the way the World operates" (Davis 2007). The second component, and the one we will focus on in this manuscript concerns the ongoing practice of researchers confronting ethical challenges without a coherent ethical paradigm guiding their actions. Specifically, we will focus on the need for a more ethically robust approach to ethical reviews of research projects.

Despite greater attention devoted to formalized training on global health ethics generally (Furin et al. 2006; Margolis et al. 2002; Bateman et al. 2001), guidance in facing the challenges of global health research is still often lacking (Stephen and Daibes 2010).

In 2009, the World Health Organization published a Casebook on Ethical Issues in International Health Research, summarizing 64 case studies, each of which raised an important and difficult ethical issue connected with planning, reviewing, or conducting health-related research. The cases prompted discussion on what ethical guidelines and processes should guide researchers from HICs working in LMICs (Cash et al. 2009). Although many of the issues identified are still relevant today, many of the cases presented are based on research that took place over three decades ago. Our work reflects upon more current research initiatives and challenges.

The case studies we present are based on our own work and comprise: 1) a project in which Canadian students conducted health promotion projects in a community in Honduras, noting, as one of the above quotes suggested, the community's frustration with the experience; 2) a research capacity-building program in South Africa, in which Canadian students and faculty worked alongside LMIC partners and in which the research ethics review 
process itself posed ethical challenges; and 3) a community-university partnered research capacity-building program linking Canadian and Ecuadorean universities, in which Ecuadorean graduate students, some working alongside Canadian graduate students, conducted community-based health research projects in Ecuadorean communities. In this last example, a new paradigm was indeed developed, and implemented within a new ethical review procedure, that we believe merits consideration as a model for others.

The three cases are progressively more detailed, and each builds on the experiences with ethical issues raised in the previous ones. Fundamental to our analysis is the recent progress that has been made related to health research in indigenous communities in Canada. For example, the Nunavut Research Institute (NRI) was formed to serve as an ethics review board that licenses all research conducted in Nunavut, Canada, an area in which the population is predominantly Inuit. ${ }^{1}$ The NRI mediates the interaction of Inuit knowledge systems which is experientially based and orally communicated, with perspectives that most outside researchers bring that appear "as practicing harsh rationality communicated through inscription" (van den Scott 2012). Van den Scott observes that it can be tempting for researchers heading to Inuit communities to offer solutions to the Inuit, but cautions that what is needed instead is an attitude of learning. Offering solutions, while well intended can disempower the Inuit as acting as knowledgeable agents who are competent in choosing their own path. The NRI urges researchers to understand what the community sees as important, which may differ substantially from what the research team sees as a effective project. The NRI, in its guide, repeatedly stresses the importance of respect for culture and local knowledge and traditions. However, as pointed out by van den Scott, the NRI offers little guidance to researchers other than demanding the respect of indigenous knowledge (van den Scott 2012).

Indeed, Canada's First Nations, after years of frustration with researchers who they felt did not seem committed to the community where the research was taking place, began to impose rules for conducting community-based research, known as "the 4 Rs": Respect, Relevance, Reciprocity and Responsibility (Kirkness and Barnhardt 2001). In 2007, the Canadian Institutes of Health Research introduced a revised set of ethical guidelines for health research involving Aboriginal People to include the $4 \mathrm{Rs}$ as a basic framework to follow. The 4 Rs stand for:

- "Respect is demonstrated toward cultures and communities by valuing their diverse knowledge of health matters and toward health science knowledge that contributes to community health and wellness.

- Relevance to culture and community is critical for the success of health research.

- Reciprocity is accomplished through a two-way process of learning and research exchange. Both community and university benefit from effective research relationships.

- Responsibility is empowerment and is fostered through active and rigorous engagement and participation." (Kirkness and Barnhardt 2001)

While ethical issues pertaining to research in aboriginal communities continue to be debated (Glass and Kaufert 2007), global health researchers can learn much from advances in aboriginal health research. Benatar and Singer suggest that the most important value driving the new paradigms for global health research is solidarity, defined as "attitudes and determination to work for the common good across the globe in an era when interdependence is greater than ever and in which progress should be defined as enhancing capabilities and social justice rather than sustaining dependency" (Benatar and Singer 2000, 2010). They note the importance of social justice and capacity building as key features that

\footnotetext{
${ }^{1}$ The Inuit people are one of Canada's First Nations, or indigenous peoples. In this article we use the terms "aboriginal", "indigenous" and "First Nations" essentially interchangeably.
} 
must be incorporated into global health research design. Meanwhile Spiegel and colleagues have called for considering "social offsets" when conducting clinical and biomedical research, to promote attention to potential measures for not only mitigating potential social harm from clinical or biomedical interventions but also increasing the focus on the social determinants of health (Spiegel et al. 2010). Breilh (2009) has advanced this further, focusing on social determination of health, noting that the individual conditions and effects are interdependent and relate profoundly to the broader societal and class conditions in which they are embedded. Therefore there is a need to expand the reductionist scope of conventional bioethics to the integral scope of the ethics of health (Breilh 2009).

Despite the various calls for more attention to ethics in global health research, there remains a dearth of literature illustrating the application of global health research ethical guidelines, let alone social offset consideration. In this article we hope to fill that gap by critically analyzing three cases in which our team has been involved. We examine what went right, what went wrong and what could have been done differently to better adhere to ethical principles that are inclusive of solidarity, respect, relevance, reciprocity, and responsibility. We question whether the current focus of ethics review boards is indeed addressing the most important ethical issues with which they should be concerned. Most importantly, we provide a concrete example of an ethical review guide that can address the concerns raised.

\section{Case 1: Student-Led Health Promotion Projects in Communities in Honduras}

Student-led global/international initiatives are growing in popularity at almost every Canadian university (The Association of Faculties of Medicine of Canada 2010; Hanson et al. 2010; Hanson 2010). Health professional students from one Canadian university concerned about the availability of primary healthcare in developing countries established a 5-year health promotion project in two rural communities in Honduras as part of a student-led international servicelearning initiative. The aim of the project was to help improve quality of life in these communities. The communities are remote and have little to no infrastructure, rely primarily on subsistence farming, and have limited access to healthcare. Working with support from a local Honduran non-governmental organization (NGO), the students conducted a needs assessment from which they developed and implemented a series of health education sessions to encourage healthy behaviours (e.g., hand washing, tooth brushing, nutrition, etc.). No formal institutional ethics approval was sought to conduct the needs assessment and to carry out the project. Students visited the communities for a month each summer over 5 years. Students also raised funds to support a few infrastructure projects such as providing cement and roofing for a community hall. The project culminated with a study that examined community members' experience working with the students and the perceived impact the project had on improving quality of life. Ethical approval to conduct the study was sought from the Canadian university that the students attended.

The communities reported that although the health education sessions were helpful, they felt that the students created expectations that went unfulfilled. During the needs assessment phase, the community identified a wide range of health and welfare issues but aside from health education initiatives, little, if anything, had been done to help the community understand the root causes of the challenges they faced, let alone begin to resolve identified health issues or address their social determination. Community members complained that the results of various needs assessment surveys conducted over the years were never shared with them nor was there a discussion of how the students would help solve the problems identified. For example, the community was told that their respiratory problems resulted from smoke due to use of biomass (wood, animal dung and crop waste) for cooking indoors. Community members were 
disappointed when the students did not "come back with stoves or medicines" and they did not "bring doctors or help build a clinic." Members of the community felt that simply providing health education talks around disease prevention and health promotion was not sufficient, particularly within the context of existing health issues that required medical intervention. Moreover, the underlying social reasons that drove these health problems were completely ignored. Other concerns that were expressed dealt with issues that may be seen as innocuous such as taking photos of the community. People stated that they "don't have pictures of their own family or have ever seen pictures of themselves, yet the students come and snap pictures every day for weeks without showing them to the community."

The Canadian students who participated in this project have become increasingly sensitive to "medical voluntourism" - projects that result in vulnerable communities serving as a means to fulfilling the students' own objectives. Students now participate in pre-departure ethics workshops that help them learn about ethical and sustainable approaches to working with communities (Dharamsi et al. 2011). This, of course, is just the start, as discussed below. Table 1 summarizes what went right, what went wrong, and what could have been done differently with respect to the two cardinal principles of global health research ethics outlined above.

\section{Case 2: Building Research Capacity to Address HIV and Tuberculosis in South Africa}

In South Africa, the burden of both HIV and tuberculosis are very high, health workers are understaffed and overworked due to the dual epidemic, and are themselves at higher risk due to occupational exposures (O'Donnell et al. 2010; Jarand et al. 2010). Focusing on internationally-identified needs (WHO et al. 2010; WHO 2010; Yassi et al. 2012), the goal of this project was to build capacity of South African researchers, students, and health practitioners on how to design, implement, and evaluate workplace-based interventions for HIV and tuberculosis. The training was delivered as a certificate program offered by a South African university in collaboration with a Canadian university. Thirty-two participants (from various healthcare backgrounds including a variety of HIV and tuberculosis prevention positions comprising nursing, infection control, community development, and occupational health) attended three 4-day in-class sessions, as well as had to design, implement and evaluate a relevant project (Global Health Research Program 2012).

The participants formed groups to conduct research projects including a hospital-wide project focusing on designing an intervention combating HIV stigma and encouraging HIV counselling and treatment; a hospital-wide project to implement a surveillance system for tuberculosis; and six group projects all involving the collection and analysis of data for prevention of transmission of HIV and tuberculosis and monitoring the effectiveness of interventions. As these were research projects, they required ethics approvals from the South African university. However, the ethics review process at the university, designed for screening randomized controlled clinical trials and the like, is extensive, requiring thorough literature reviews, detailed protocols, and methodological clarity beyond the skill set of these busy poorly-resourced practitionerresearchers in-training, who had limited time to devote to conducting these projects within the one year time-frame of the course. This itself posed a dilemma for the team - should the Canadians, with input from local university colleagues, write the ethics approvals for our LMIC trainees? The team decided to create an ad hoc ethics approval process, tailored to the type of workplace interventions being designed, with ethics committee members consisting of experienced academics attuned to the reality of the trainees.

Three Canadian graduate students (one PhD and two Masters) have been conducting their graduate research on various aspects of this program, all with research ethics approval from 
Table 1 Student-led health promotion projects in communities in Honduras

Enhancing Local Capabilities

What went right a) A needs assessment was carried out helping the community identify its issues and priorities

b) A local NGO was consulted

c) Ethics approval was sought to carry out the concluding study to assess community members' viewpoints and experiences of the project

What went wrong

What could have been done a) Students with good intentions "parachuted" into a community without explicit permission from the community itself

b) Community members not involved in needs assessment, program planning and implementation

c) Doing to rather than with community resulting in lack of meaningful engagement and participation and creation of false expectations

d) There was no ethical review process created locally

a) Consultation not only with local NGO but also with community members

b) Needs assessment, program planning and implementation carried out in collaboration with community members

c) Ethics approval for project and study from Canadian as well as host country institutions
Promoting Social Justice

a) Students from high income countries concerned about global health disparities and the desire to respond

b) Funding was raised to support community identified infrastructure priorities

c) Students interested in global health outreach take an ethics workshop prior to international engagement

a) Ethics review for end of project study motivated by the desire to publish project interventions and results

b) The project stopped when funding for student travel stopped

c) Students took pictures without consent

d) Little real change in the community pertaining to existing and on-going health concerns

e) No attempt was made to address underlying social determination of health

a) Efforts could have been made to understand the social, economic,political, and cultural context of the community

b) The social determination of the health problems identified could have been incorporated into the intervention

c) A plan to address the immediate as well as underlying social determination of the health problems could be been developed with local partners

their university. Several challenges were documented; most notable was the huge burden HIV was taking not only on the patient population served by the trainees but on the trainees themselves and their own families. Other difficulties related to the lack of time to conduct the research, given the day-to-day work demands. The main challenge, identified early, was the lower-than-expected level of research skills of the participants recruited. While knowledge of the subject matters (HIV, tuberculosis, infection control, workforce health, etc.) was at a satisfactory baseline, most participants had no experience conducting a formal research study. Another difficulty encountered was the expectation for further offerings of the programme for others that could not be included in this one-time offering. Moreover, although one of the projects in the overall research program does indeed address the macro economic issues that drive HIV and TB (Global Health Research Program 2012), and the ethics review process developed by our team for these projects did address issues such as involvement of all stakeholders and local capacity-building, it failed to squarely address the 
social determination of the problems being addressed. Table 2 summarizes our analysis of what went right, what went wrong, and what could have been done better regarding the two aspects of global health research ethics discussed above.

\section{Case 3: Community-Action Research on Environmental Health Issues in Ecuador}

A 6-year partnership between a Canadian university and four universities in Ecuador, funded by the Canadian International Development Agency, was initiated in 2004 to strengthen capacities for conducting research-informed interventions to address environmental health concerns throughout the region (Spiegel et al. 2011). Although no formal research ethics approval processes existed for this type of community-based health research in the Ecuadorean universities in this partnership, the local and international team collectively decided to require that the research conducted by all thirty Ecuadorean Master's students (ten from each of the three universities in which Master's programs were being offered) in partial fulfilment of graduate degrees within this partnership, had to be not only scientifically sound but also responsive to the needs of the community, explicitly addressing how local stakeholders were consulted and involved in the projects (Yassi et al. 2007; Spiegel et al. 2007a, b; Parkes et al. 2009).

Students' research focused on dengue-control (3 student theses); water and sanitation (7); ecological restoration and sustainable agriculture (5); pesticide use (4); waste management (3); mining contamination (3); lead poisoning and other occupational health hazards (3); ancestral birth practices (1); antibiotics resistance (1) and medical school curriculum development based on an ecosystem approach to health (1). Several Canadian graduate students, medical residents as well as undergraduate medical students were also involved in the research, three of whom conducting their doctoral dissertations within these community research projects.

In reviewing the "ethics" section of the 30 Master's thesis profiles presented before the studies were undertaken, the most common ethical issues addressed related to informed consent of the individual participants. However, by far the most common concern among the researchers, and indeed one that was actually evident in all of the 30 research projects, was how to facilitate meaningful involvement of the community to ensure that the researchers properly considered the social, economic, political and cultural context in which the research was being conducted and allowed for community-based decision-making. This was necessary not only for the sake of conducting high quality research, but also because measures had to be developed not only to ensure that no harm would result from the research project, at both the individual as well as community level, but that the vision of the community would be reflected in the research protocol. This was especially true for studies in which existing economic activities of community members (e.g. small-scale gold mining, applying lead to glaze tiles and bricks, using pesticides to improve crops, etc.) could be construed as harming the community's health and the environment; it also represented an opportunity to advance sustainable development.

A second common ethical issue related to interculturality in research and addressing cross-cultural factors, especially given that many of the communities were Indigenous, or included large Indigenous populations. As four of the Ecuadorean Master's students were themselves Indigenous, and from the communities in which the research was being conducted, this was not insurmountable, but still posed ethical challenges for the team. One student-led project, focusing on assessing the environmental and health consequences of solid waste disposal practices with the ultimate goal of creating a municipal recycling system to reduce health hazards and environmental contamination, provides an illustrative example of the kind of ethical issues encountered. In the rural farming community of Curgua, Ecuador, the adjacent municipal government operates a garbage disposal site where 
Table 2 Building research capacity to address HIV and Tuberculosis in South Africa

\begin{tabular}{|c|c|c|}
\hline & Enhancing Local Capabilities & Promoting Social Justice \\
\hline \multirow[t]{5}{*}{$\begin{array}{l}\text { What went } \\
\text { right }\end{array}$} & a) A certificate program was established & $\begin{array}{l}\text { a) Course material incorporated social } \\
\text { justice issues }\end{array}$ \\
\hline & $\begin{array}{l}\text { b) A process was created whereby Northern } \\
\text { faculty members and students assisted the } \\
\text { LMIC students }\end{array}$ & $\begin{array}{l}\text { b) Northern faculty and students were } \\
\text { keenly aware of and attempted to be } \\
\text { respectful of the LMIC concerns }\end{array}$ \\
\hline & $\begin{array}{l}\text { c) University-Community linkages were } \\
\text { strengthened }\end{array}$ & $\begin{array}{l}\text { c) The ad hoc ethics review process } \\
\text { included required community consultation }\end{array}$ \\
\hline & $\begin{array}{l}\text { d) An ad hoc ethics approval process was } \\
\text { created for the projects within this program }\end{array}$ & $\begin{array}{l}\text { d) Funds were obtained to address some of } \\
\text { the problems identified in the research } \\
\text { and conduct follow-ups }\end{array}$ \\
\hline & & $\begin{array}{l}\text { e) A new project was launched to examine } \\
\text { what could be done at the macro socio- } \\
\text { economic level }\end{array}$ \\
\hline \multirow[t]{3}{*}{$\begin{array}{l}\text { What went } \\
\text { wrong }\end{array}$} & $\begin{array}{l}\text { a) Teaching methodological rigour to conduct } \\
\text { good quality research and obtain research } \\
\text { funding after the end of the program was not } \\
\text { sufficient }\end{array}$ & $\begin{array}{l}\text { a) While efforts were made to address these } \\
\text { issues, the huge problem of under-staffing, } \\
\text { poor infrastructure and inadequate } \\
\text { resources to sustain the programs still } \\
\text { needs to be addressed }\end{array}$ \\
\hline & $\begin{array}{l}\text { b) Inadequate attention was devoted to } \\
\text { institutional strengthening by way of more } \\
\text { thoroughly involving senior faculty members }\end{array}$ & $\begin{array}{l}\text { b) The reasons underlying the above factors } \\
\text { were not acknowledged in the context of } \\
\text { these projects }\end{array}$ \\
\hline & $\begin{array}{l}\text { c) No attention was given to creating a } \\
\text { sustainable ethical review process }\end{array}$ & \\
\hline \multirow[t]{2}{*}{$\begin{array}{l}\text { What could } \\
\text { have been } \\
\text { done }\end{array}$} & $\begin{array}{l}\text { a) The program was too ambitious with too } \\
\text { many students in each program and too } \\
\text { many universities involved -such that } \\
\text { inadequate attention was devoted to serious } \\
\text { skill-building - better student selection may } \\
\text { have been warranted }\end{array}$ & $\begin{array}{l}\text { a) Fewer participants should have been } \\
\text { involved in the research, with a more } \\
\text { thorough assessment made before the } \\
\text { program began as to the likelihood of the } \\
\text { team being able to build sufficient } \\
\text { capacity for the gains to be sustained after } \\
\text { the research ended }\end{array}$ \\
\hline & $\begin{array}{l}\text { b) More attention should have been devoted to } \\
\text { institutional strengthening for research ethics } \\
\text { reviews }\end{array}$ & $\begin{array}{l}\text { b) The social determination of HIV and TB } \\
\text { should have been at least acknowledged in } \\
\text { each of the projects }\end{array}$ \\
\hline
\end{tabular}

all the solid waste from the town is taken. In this setting, "minadores" (Spanish for "mine diggers" but referring to those who "mine" the waste) sort and collect materials from the town's garbage for reuse, recycling, and resale. The minadores, often including children and pregnant women, are exposed to biological hazards, sharps, and a host of other risks from organic and inorganic wastes. Nevertheless, the minadores were wary of any intervention, even if the intent was a much safer recycling system and stable employment conditions in a proposed micro-enterprise, for fear it would deprive them of their livelihood.

Through collaborations between researchers, the minadores, community representatives and health professionals, it was decided that the research must collect data not only on direct health problems, but also on social and economic concerns of all affected parties. The outcome of the research from the researchers' perspectives could easily have been restricted to documenting environmental and health problems, implementing the recycling program and cleaning up the waste site. However, this would have overlooked the wishes of the minadores to retain their access to the garbage disposal site, as these families would have suffered further economic hardships if the site were closed. In this sense, it was not only the value of effectiveness and 
efficiency of improving waste management that was central, but the consideration of equity implications for all those involved, including the concerns of marginalized populations.

By making it an ethical imperative that the research take account of community perceptions of positive and negative consequences associated with the intervention being studied, the research team urged the municipal government to support the creation of a microbusiness on the site to allow the minadores to continue their work, but more safely, while also effectively recycling and reusing the garbage. For example, team members worked hard to ensure that funding for purchasing personal protective equipment for the minadores was included in funding provided for the intervention. The knowledge gained from this study has been shared globally (Mena et al. 2010) and other communities have expressed interest in replicating this project elsewhere. Although, institutional ethics review boards may not have stipulated that the research must be careful to do no harm to the communities potentially affected by the research results, the application of the 4 Rs in our case required a socially responsible approach - one that provided reciprocal benefits to the community, and that was respectful of their lifestyle choices.

Similar issues arose in virtually all the projects conducted in this Canadian-Ecuadorean community health research training program, as noted above. Other examples include a study of mercury contamination from small-scale mining, and another on lead poisoning related to tile and brick making. In both cases, community members were concerned that the outcome of the study could put their livelihoods in jeopardy. Thus the team is continuing to work with the community to implement measures to alleviate this concern. For the small-scale miners, Canadian contacts, as well as government officials, mining associations and international expertise were brought together in a workshop following the completion of the theses to disseminate the results and promote action addressing the concerns of the community. Indeed the students who undertook the research in this mining community signed an agreement with the community before commencing the research promising that measures would be taken in this regard. In the community with lead contamination, medical students and faculty from Canada are now working with counterparts from University of Cuenca to eliminate lead glazes and attend to the health needs of the study community. While this was essential in observing the 4 Rs, the current ethics review process in most institutions does not generally inquire into the potential social and economic as well as health consequences for the participating communities, let alone assure proper follow-up. (We note that the hazardous practices of some Canadian mining companies in Latin America [(Sacher and Baez 2011)] raise important additional dimensions in considering ethical issues when Canadian researchers and students attempt to conduct health research in mining communities; we return to this issue in the discussion.)

An additional concern relevant for ethics review boards arose in several projects in which Indigenous traditions differ from common Western approaches. For example, one research project conducted by an Indigenous nurse sought to document traditional birth practices and how these could be better promoted. Some of these practices have never been formally studied with respect to effectiveness and safety. Institutional ethics review boards might question these practices, and deem the research unethical to conduct. The student indicated to the program committee that the overall cultural importance of retaining traditional values, combined with the low probability of harm from these practices if conducted with the proper safeguards, should suffice to conduct research on how to better promote this Ancestral knowledge in reproductive health within the public health system that operates within Western standards of practice (Cárdenas 2005; Mideros 2011). Again, ethics review approval processes might have disregarded the cultural importance of traditional practices in ascertaining the relative benefit and potential harm of conducting research on knowledge translation of traditional practices. Thus, research ethics boards would need to systematically 
inquire not only about potential social, economic and health positive and negative impacts, but also possible positive and negative cultural impacts of the research.

Although the Ecuadorean student projects were not subjected to the ethical review process at the Canadian university, the three Canadian doctoral student theses, were, of course, submitted for research ethics board approval. These reviews, although questioning the informed consent process and data security issues, made no inquiry into the possible overall impact on the socio-economic and cultural wellbeing of the community. Notably there is an explicit question at Canadian university research ethics boards' regarding whether an Aboriginal community is involved and, if so, requesting a copy of the research agreement with the community, or description of the community consent process. But there are no questions regarding community engagement for other contexts.

In an effort to follow-up on the concerns identified, several grant proposals were written. The one emerging from the three theses related to dengue control was funded by an international research funding agency to further trial prevention efforts in highly exposed communities. The funder, however, noted that a more official ethics approval board was needed. Noting that the Ecuadorean existing ethics approval process for randomized clinical trials was not appropriate for this community-based intervention study, the lead Ecuadorean researcher (co-author JB), with some assistance from Canadian team members (co-authors AY and JS), proposed a radical new ethics approval guide, embracing the principles articulated above, reflecting an appreciation of the social determination of health. Table 3 outlines what went right and wrong with this experience. Appendix 1 outlines the questions posed in this guide, to assess the merit of proposed research projects submitted for ethics review. These questions, including an assessment of the social implications of the research and its various correlates, can apply equally to research funded internationally or locally. This guide (Breilh et al. 2012) has already been endorsed and applied by the Ecuadorian Academy of Medicine's Ethical Committee; the first research project assessed using the need guidelines was the evaluation of an internationally-funded research project on dengue control, noted above (Spiegel et al. 2007a, b).

\section{Discussion}

The vast majority of universities in HICs have institutional research ethics review boards, consisting of one or more committees formally designated to approve, monitor, and review research projects involving humans, including community-based health research. Most HICs ethics research boards have been actively addressing procedural correctness (Ellis 1999), including privacy, data security and recruitment. However, our own experience, as well as what we gleaned from our review of the literature, indicates that despite strides made in protecting individual rights in research studies, collective rights of vulnerable communities seem rarely considered in ethics reviews.

For a community, particularly one that governs itself from collective versus individualistic cultural perspectives, a common "ethical" violation from the perspective of the community is "drive-by data gathering", with nothing done, or even proposed about the problems identified through the study (Racine 2003). This was illustrated in the quote at the beginning of the article, and a sentiment we heard repeatedly in our community visits in Ecuador as part of the thesis assessment process. Researchers, all too often, do not even properly share findings with the community (Lairumbi et al. 2011; Lavery et al. 2010). More commonly, researchers do little to help strengthen capacity within communities to address 
the problems identified. While research granting agencies are now encouraging substantial budgets to be included in research proposals for dissemination of findings, many researchers still focus their dissemination efforts narrowly on peer-reviewed scientific publications, rather than community knowledge sharing (Lairumbi et al. 2011, 2012). Moreover, the potential for research to perpetuate blaming, stereotyping, paternalism, exploitation and discrimination is a concern that requires serious attention in order to ensure that neither individual participants nor the community to which they belong are hurt by the study (Reimer Kirkham and Anderson 2002; Reimer Kirkham et al. 2002). Even more important, ensuring that communities are not overly harmed by the research is not sufficient; without a sense of solidarity and serious efforts to build local capacity (Bhutta 2002) at the research site to address the problems identified, the gap not only between the academy and the broader society it was designed to serve (Yassi et al. 2010), but also between HIC and LMICs may well be perpetuated.

Researchers who work in significantly different socioeconomic and cultural settings than their own are bound to experience ethical challenges. Problems arise when there is lack of clear communication about the scope, plan and capacity of a project, as well as the implications of its insertion into the local dynamics that the local people are building. When entering an unfamiliar setting, background knowledge and experience with the historical, sociocultural and political environment is essential in ensuring the work that will be done is relevant, carried out respectfully and sustainable (Stephen and Daibes 2010). However, despite good intentions, efforts will continue to be, and perceived to be, paternalistic, if there is insufficient collaboration with local stakeholders; this can be even worse if it creates false hopes and lead to failed initiatives (Chandiwana and Ornbjerg 2003; Costello and Zumla 2000). As was learned from health research in aboriginal communities (Reimer Kirkham and Anderson 2002; Reimer Kirkham et al. 2002), misunderstandings happen when community members do not direct, or are at least extensively involved from the outset, in deciding whether students or researchers should come to their community and for what purpose. As we found in our own experience, researchers and/or students who enter a community without prior negotiation of the purpose and scope of a project, or without creating a genuine partnership with local individuals or organizations, may do more harm than good.

Despite academic efforts to bring global health to the forefront (Vermund et al. 2008; Quinn 2008; Lorntz et al. 2008), the root causes of inequalities affecting health that confront vulnerable communities in LMICs are rarely considered in academic medical research. Vulnerable communities can become a means to the researchers' ends (Houpt et al. 2007) instead of first serving the community identified needs and empowerment interests (Sherraden et al. 2008). The important debate on research ethics and global health concerning issues of exploitation and cultural imperialism that emerged decade ago continues to be no less a source of concern over a decade later (Benatar 1998). The values that guided our review are consistent with those proposed by others (Ijsselmuiden et al. 2010). Whilst work is ongoing on creating international standards for research ethics (Resnik 2009), such guidelines will have the desired impact if researchers hold social accountability at the forefront (Boelen and Woollard 2009; Ballantyne 2010), and Research Ethics Boards require this as a pre-condition for granting ethics approvals (Breilh 2009; Garrafa et al. 1999).

Aboriginal peoples in Canada have taken measures to require social accountability from researchers who come to their communities, and a research ethics board in Ecuador now requires that the research process (whether conducted by local researchers alone, or in partnership with researchers from HICs) considers community benefits and harms rather than just 
Table 3 Community-action research on environmental health issues in Ecuador

\begin{tabular}{|c|c|c|}
\hline & Enhancing Local Capabilities & Promoting Social Justice \\
\hline \multirow[t]{5}{*}{$\begin{array}{l}\text { What went } \\
\text { right }\end{array}$} & $\begin{array}{l}\text { a) Masters Programs were established in } 3 \\
\text { universities and a } \mathrm{PhD} \text { program in one }\end{array}$ & $\begin{array}{l}\text { a) Course material focused heavily on } \\
\text { social justice issues }\end{array}$ \\
\hline & $\begin{array}{l}\text { b) A process was created whereby Northern } \\
\text { faculty members and students assisted the } \\
\text { LMIC students }\end{array}$ & $\begin{array}{l}\text { b) Northern faculty and students were } \\
\text { keenly aware of and attempted to be } \\
\text { respectful of the LMIC concerns }\end{array}$ \\
\hline & $\begin{array}{l}\text { c) University-Community linkages were } \\
\text { established }\end{array}$ & $\begin{array}{l}\text { c) Funds were obtained to address some } \\
\text { of the problems identified in the research } \\
\text { and conduct follow-ups }\end{array}$ \\
\hline & $\begin{array}{l}\text { d) An ad hoc ethics approval process was } \\
\text { created for the projects within this program }\end{array}$ & $\begin{array}{l}\text { d) The ethics review process established } \\
\text { includes a consideration of social justice } \\
\text { issues }\end{array}$ \\
\hline & $\begin{array}{l}\text { e) Eventually a formal ethical approval process } \\
\text { was implemented locally, that included a } \\
\text { consideration of local capacity-building }\end{array}$ & \\
\hline \multirow[t]{3}{*}{$\begin{array}{l}\text { What went } \\
\text { wrong }\end{array}$} & $\begin{array}{l}\text { a) Teaching methodological rigour to conduct } \\
\text { good quality research and obtain research } \\
\text { funding after the end of the program was not } \\
\text { sufficient. }\end{array}$ & $\begin{array}{l}\text { a) Expectations were raised in some } \\
\text { communities that could not be addressed } \\
\text { across the board - largely to the over- } \\
\text { ambitiousness of the undertaking and the } \\
\text { capacity of the Northern team to continue } \\
\text { to mentor only a few of the participants } \\
\text { and their community projects after the } \\
\text { end of the program }\end{array}$ \\
\hline & $\begin{array}{l}\text { b) Inadequate attention was devoted to } \\
\text { institutional strengthening by way of more } \\
\text { thoroughly involving senior faculty members; }\end{array}$ & \\
\hline & $\begin{array}{l}\text { c) No attention was given to creating a } \\
\text { sustainable ethical review process- until } \\
\text { recently }\end{array}$ & \\
\hline \multirow[t]{2}{*}{$\begin{array}{l}\text { What could } \\
\text { have been } \\
\text { done }\end{array}$} & $\begin{array}{l}\text { a) The program was too ambitious with too } \\
\text { many students in each program and too many } \\
\text { universities involved -such that inadequate } \\
\text { attention was devoted to serious skill-building }\end{array}$ & $\begin{array}{l}\text { a) Fewer communities should have been } \\
\text { involved in the research, with an } \\
\text { assessment made before each project } \\
\text { began as to the likelihood of the team } \\
\text { being able to address the problems } \\
\text { identified in the research and/or build } \\
\text { sufficient capacity within the community } \\
\text { to do so after the research ended }\end{array}$ \\
\hline & $\begin{array}{l}\text { b) More attention should have been devoted to } \\
\text { institutional strengthening for research ethics } \\
\text { reviews much sooner }\end{array}$ & \\
\hline
\end{tabular}

individual harms, and thoroughly assesses cultural as well as socioeconomic and health implications to the community.

The lack of attention by research ethics review boards to the substantive collective issues identified is problematic. And the situation may be no better among researchers from LMICs; of 670 researchers surveyed in LMICs by Hyder and colleagues only $56 \%$ reported that their research had been reviewed by a local institutional review board or health ministry (Hyder et al. 2004). For this reason, the efforts in Ecuador are particularly noteworthy.

The Canadians involved hope to use Ecuador's initiative as an example to emulate in order to strengthen the ethics approval process across Canada as well. We therefore 
strongly recommend that research ethics boards, both in HICs and LMICs, heed the concern expressed by Benatar and Singer (Benatar and Singer 2010), among others. Otherwise, research efforts in vulnerable communities may well be, and/or be seen to be "unethical" - to the detriment of the community-site of the research, and to worldknowledge generally.

Acknowledgments The authors wish to thank Canadian, Honduran, South African and Ecuadorean colleagues, staff, students and communities who are participating with us in this undertaking. Funding/Support: Our work was funded in part through the Peter Wall Institute for Advanced Studies at the University of British Columbia who recognized Dr. Breilh as an International Visiting Research Scholar; Dr. Dharamsi via the Teaching and Learning Enhancement Fund to study the ethical implications of international engagement and service learning; the research capacity-building program in South Africa was funded by the Global Health Research Initiative in Canada (a collaboration of the Canadian Institutes for Health Research, the Canadian International Development Agency [CIDA], the International Development Research Centre, and Health Canada); the project in Ecuador was supported by CIDA; and the Canada Research Council provides salary support for Dr. Yassi.

Disclaimer The opinions expressed in this article are those of the authors alone and do not reflect the views of the funding agencies or partners.

\section{Appendix 1. The 15 questions to be asked to assess research projects within the new ethical review board in Ecuador}

Academia Ecuatoriana de Medicina

Research Ethics Committee

GUIDE TO ETHICS OF NON-EXPERIMENTAL RESEARCH PROJECT EVALUATION

This guide for evaluation of non-experimental research projects in the fields of clinical and epidemiological partner, is formulated in accordance with the relevant regulation on the status of the Academy.

Non-clinical research projects

Project title::

Project period (start and end dates):

Start date:

day [ ] month [ ] year [ ]

Scheduled end date: day [ ] month [ ] year [ ] 
Responsible institution(s):

Institution 1:

Institution 2:

Others:

Principal Investigator(s), responsible for project:

Principal Investigator (PI):

Co - Principal Investigator (CPI):

Other members of the research team by country:

Country 1 :

Country 2:

Others:

Principal Source of Funding:

Other Sources of Funding and Resources:

Conflicts of interest (real or potential), affecting objectivity and ethical principles of research in this project:

Some of the researchers receive personal economic benefits, in addition to the normal fees for referred scientific work in the project being undertaken that can influence results that can benefit these or other enterprises or institutions.

YES [ ] NO [ ]

Comments (optional):

Some of the researchers receive economic, political, cultural or promotional benefits for any organization or entity that has links with the research project that is being undertaken.

YES [ ] NO [ ]

Comments (optional):

Any other conflict of interest affecting objectivity or ethical principles of research in this project:

YES [ ] NO [ ]

Comments (optional):

There exists a beneficial character of the project in relation to its ability to offer and develop knowledge, skills and attitudes that constitute an immediate or potential benefit for the population/community that has accepted to be part of the project:

YES [ ] NO [ ] 
Comments (optional):

Absence of effects and processes that are harmful to life or pathogenic to humans, that would be caused as a result of the application of the procedures, substances or elements that are part of the scientific project being undertaken, whose danger has already been established by science or is being discussed in the context of the precautionary principle.

YES [ ] NO [ ]

Comments (optional):

Social and cultural equity of the project:

Respect for the values, knowledge, and culture of the population / community that is involved in the project

YES [ ] NO [ ]

Comments (optional):

Strengthening of local or personal capacities of those who are involved in study to deal with the problem that is being addressed.

$$
\text { YES [ ] NO [ ] }
$$

Comments (optional):

Reciprocity in the production and assimilation of knowledge about the problem both from the researchers towards the population as well as from the population to the researchers.

YES [ ] NO [ ]

Comments (optional):

Scientific validity of the project

The study design incorporates its methodological elements with rigor, clarity, sufficiency and current knowledge to ensure an objective process of controlled, systematized and safe procedures that are oriented to evidentiary purposes and the need for producing knowledge in line with the study's scientific questions and hypotheses.

YES [ ] NO [ ]

Comments (optional):

The project is conducted from a disciplinary perspective consistent with the current "State of the art":

YES [ ] NO [ ]

Comments (optional):

The project applies necessary scientific and technical knowledge that is consistent with a design that involves a reasonable use of resources and cost/benefit ratio:

YES [ ] NO [ ]

Comments (optional): 
The project establishes a transparent, ethical and safe management approach and for purposes of informed consent:

Applies norms of informed consent on procedures in general and on the management of information and data.

YES [ ] NO [ ]

Comments(optional):

The information that is collected by this study on personal data is managed with strict compliance with the principle of confidentiality.

$$
\text { YES [ ] NO [ ] }
$$

Comments (optional):

The data bases are managed exclusively in institutional contexts with access limited to team members.

$$
\text { YES [ ] NO [ ] }
$$

Comments (optional):

\section{FINAL ETHICAL ASSESSMENT}

Project fulfills projected ethical standards:

Project requires some improvements to be approved:

Project fulfills projected ethical standards

and does not merit ethical approval:

Signatures of designated reviewers

\section{Evaluator 1:}

Name:

Signature:

Evaluator 2:

Name:

Signature:

Evaluator 3:

Name:

Signature:

Date: day [ ] month [ ] year [ ]

Signature of the president of the Ecuadorian Academy of Medicine

Name:

Signature: 


\section{References}

Ballantyne, A. J. (2010). How to do research fairly in an unjust world. The American Journal of Bioethics, $10(6), 26-35$.

Bateman, C., Baker, T., Hoornenborg, E., \& Ericsson, U. (2001). Bringing global issues to medical teaching. The Lancet, 358(9292), 1539-1542.

Benatar, S. (1998). Imperialism, research ethics and global health. Journal of Medical Ethics, 24(4), $221-222$.

Benatar, S. R., \& Singer, P. A. (2000). A new look at international research ethics. BMJ, 321(7264), 824-826.

Benatar, S. R., \& Singer, P. A. (2010). Responsibilities in international research: a new look revisited. Journal of Medical Ethics, 36(4), 194-197.

Bhutta, Z. A. (2002). Ethics in international health research: a perspective from the developing world. Bulletin of the World Health Organization, 80(2), 114-120.

Boelen, C., \& Woollard, B. (2009). Social accountability and accreditation: a new frontier for educational institutions. Medical Education, 43(9), 887-894.

Breilh, J. (2009). Science by contract: The science and power relation, Chapter of Technology, Science and Society. In Ecuadorian Constitution (pp. 7-26). Ecuador. Hacia una construccion emancipadora del derecho a la salud. In Programa Andina de Derechos Humanos, compilador. Informe sobre derechos humanos. [Towards emancipatory construction of the right to health. Andean program in human rights] (pp. 263-83). Ecuador: University Andina Simon Bolivar.

Breilh, J., Spiegel, J. M., \& Yassi, A. (2012). Guía para la Evaluación Ética de Proyectos de Investigación No Experimentales. Quito: Academia Ecuatoriana de Medicina.

Canadian Institutes of Health Research (CIHR) (2007). CIHR guidelines for health research involving aboriginal people. Available at http://www.cihr-irsc.gc.ca/e/29134.html

Cárdenas, O. (2005). Evaluación Comparativa del Parto Vertical y Convencional. Cuenca: Universidad de Cuenca.

Cash, R., Wikler, D., Saxena, A., \& Capron, A., (Eds.) Casebook on Ethical Issues in International Health Research: World Health Organization, Geneva. 2009. Available at http://whqlibdoc.who.int/publications/ 2009/9789241547727_eng.pdf

Chandiwana, S., \& Ornbjerg, N. (2003). Review of North-South and South-South cooperation and conditions necessary to sustain research capability in developing countries. Journal of Health, Population, and Nutrition, 21(3), 288-297.

Costello, A., \& Zumla, A. (2000). Moving to research partnerships in developing countries. British Medical Journal, 321, 827-829.

Davis, D. (2007). The secret history of the war on cancer. New York, NY: Basic Books.

Dharamsi, S., Osei-Twum, J., \& Whiteman, M. (2011). Socially responsible approaches to international electives and global health outreach. Medical Education, 45(5), 530-531.

Ellis, G. B. (1999). Keeping research subjects out of harm's way. JAMA: The Journal of the American Medical Association, 282(20), 1963-1965.

Furin, J., Farmer, P., Wolf, M., Levy, B., Judd, A., Paternek, M., et al. (2006). A novel training model to address health problems in poor and underserved populations. Journal of Health Care for the Poor and Underserved, 17(1), 17-24.

Garrafa, V., Diniz, D., \& Guilhem, D. (1999). Bioethical language and its dialectics and idiolectcs. Cadernos de Saúde Pública, 15(Suppl 1), 35-42.

Glass, K. C., \& Kaufert, J. (2007). Research ethics review and aboriginal community values: can the two be reconciled? Journal of Empirical Research on Human Research Ethics: An International Journal, 2(2), $25-40$.

Global Health Research Program (GHRP) UBC (2012). Homepage. www.ghrp.ubc.ca, Website, accessed September 10, 2012.

Hanson, L. (2010). Global citizenship, global health, and the internationalization of curriculum a study of transformative potential. Journal of Studies in International Education, 14(1), 70-88.

Hanson, L., Harms, S., \& Plamondon, K. (2010). Undergraduate international medical electives: some ethical and pedagogical considerations. Journal of Studies in International Education, 15(2), 171-185.

Houpt, E., Pearson, R., \& Hall, T. (2007). Three domains of competency in global health education: recommendations for all medical students. Academic Medicine, 82(3), 222-225.

Hyder, A. A., Wali, S. A., Khan, A. N., Teoh, N. B., Kass, N. E., \& Dawson, L. (2004). Ethical review of health research: a perspective from developing country researchers. Journal of Medical Ethics, 30(1), 6872.

Ijsselmuiden, C. B., Kass, N. E., Sewankambo, K. N., \& Lavery, J. V. (2010). Evolving values in ethics and global health research. Global Public Health, 5(2), 154-163. 
Jarand, J., Shean, K., O’Donnell, M., Loveday, M., Kvasnovsky, C., van der Walt, M., et al. (2010). Extensively drug-resistant tuberculosis (XDR-TB) among health care workers in South Africa. Tropical Medicine \& International Health, 15(10), 1179-1184.

Kirkness, V. J., \& Barnhardt, R. (2001). First nations and higher education: The four R's - respect, relevance, reciprocity, responsibility. Knowledge across cultures: A contribution to dialogue among civilizations. $\mathrm{R}$. Hayoe and J. Pan. Hong Kong, Comparative Education Research Centre, The University of Hong Kong.

Lairumbi, G. M., Michael, P., Fitzpatrick, R., \& English, M. C. (2011). Ethics in practice: the state of the debate on promoting the social value of global health research in resource poor settings particularly Africa. BMC Medical Ethics, 12, 22.

Lairumbi, G. M., Parker, M., Fitzpatrick, R., \& English, M. C. (2012). Forms of benefit sharing in global health research undertaken in resource poor settings: a qualitative study of stakeholders' views in Kenya. Philosophy, Ethics, and Humanities in Medicine, 7(1), 7-15.

Lavery, J., Tinadana, P., Scott, T., Harrington, L., Ramsey, J., Ytuarte-Nuñez, C., et al. (2010). Towards a framework for community engagement in global health research. Trends in Parasitology, 26(6), 279-283.

Lorntz, B., Boissevain, J. R., Dillingham, R., Kelly, J., Ballard, A., Scheld, W. M., et al. (2008). A transuniversity center for global health. Academic Medicine, 83(2), 165-172.

Margolis, C. Z., Deckelbaum, R. J., Henkin, Y., \& Alkan, M. (2002). Bringing global issues to medical teaching. The Lancet, 359(9313), 1253-1254.

Mena, J., Orrego, E., Spiegel, J. M., Rojas-Orrego, T., Orrego, P., \& Yassi, A. (2010). Is Progress Always Progressive? Addressing the environmental, social, health and economic concerns of women who make their living from solid waste disposal sites in Ecuador - a multimedia presentation. Paper presented at the EcoHealth 2010 Conference, London, England, 18 - 20 August.

Mideros, R. (2011). La Atención Intercultural Obstétrica y sus Efectos [Intercultural Obstetric Care and its Effects]. Quito: Universida Andina Simón Bolívar. Thesis in partial fulfillment of Doctorate in Collective Health, Environment and Society.

Montgomery, L. (1993). Short-Term Medical Missions: Enhancing or Eroding Health? Missiology: An International Review, 21(3), 33-41.

O'Donnell, M. R., Jarand, J., Loveday, M., Padayatchi, N., Zelnick, J., Werner, L., et al. (2010). High incidence of hospital admissions with multidrug-resistant and extensively drug-resistant tuberculosis among South African health care workers. Annals of Internal Medicine, 153(8), 516-522.

Parkes, M., Spiegel, J. M., Breilh, J., Cabarcas, F., Huish, R., \& Yassi, A. (2009). Building sustainable capacity to promote the health of marginalized populations through international collaboration: Examining community-oriented training innovations in Ecuador. Bulletin of the World Health Organization, 87(4), 245-324.

Quinn, T. C. (2008). The Johns Hopkins Center for Global Health: transcending borders for world health. Academic Medicine, 83(2), 134-142.

Racine, L. (2003). Implementing a postcolonial feminist perspective in nursing research related to nonWestern populations. Nursing Inquiry, 10(2), 91-102.

Reimer Kirkham, S., \& Anderson, J. (2002). Postcolonial nursing scholarship: From epistemology to method. Advances in Nursing Science, 25(1), 1-17.

Reimer Kirkham, S., Smye, V., Tang, S., Anderson, J., Browne, A., Coles, R., et al. (2002). Rethinking cultural safety while waiting to do fieldwork: Methodological implications for nursing research. Research in Nursing and Health, 25, 222-232.

Resnik, D. (2009). International standards for research integrity: an idea whose time has come? Accountability in Research, 16, 218-228.

Roth, D. (2001). Humanitarian aid and medical research: an illusion of dichotomy in international health. CMAJ Canadian Medical Association Journal, 164(13), 1862-64.

Sacher, W., \& Baez, M. (2011). Revision critica parcial del Estudio de impacto ambiental para la fase de beneficio del Proyecto minero de Cobre Mirador de la empresa Ecuadcorriente, Ecuador. Quito, Ecuador: Accion Ecologica.

Sherraden, M. S., Lough, B., \& Moore McBride, A. (2008). Effects of international volunteering and service: individual and institutional predictors. Voluntas: International Journal of Voluntary and Nonprofit Organizations, 19(4), 395-421.

Spiegel, J. M., Bonet, M., Ibarra, A., Pagliccia, N., Ouellette, V., \& Yassi, A. (2007a). Social and environmental determinants of Aedes aegypti infestation in Central Havana: Results of a case-control study nested in an integrated dengue surveillance program in Cuba. Tropical Medicine \& International Health, 12(4), 503-10.

Spiegel, J. M., Breilh, J., Parkes, M., Bowie, W., Pearce, L., \& Yassi, A. (2007b). UBC's experience in building partnerships for development in Ecuador - 1. From the top down: Establishing sustainable community-focused networks. Paper presented at the 11th UNESCO-APEID International Conference 
"Reinventing Higher Education: Toward Participatory and Sustainable Development, Bangkok, Thailand, December $12-14$

Spiegel, J. M., Dharamsi, S., Wasan, K., Yassi, A., Singer, B., et al. (2010). Which new approaches to tackling neglected tropical diseases show promise? PLoS Medicine, 7(5), e1000255.

Spiegel, J. M., Breilh, J., Beltran, E., Parra, J., Solis, F., Yassi, A., et al. (2011). Establishing a community of practice of researchers, practitioners, policy-makers and communities to sustainably manage environmental health risks in Ecuador. BMC International Health and Human Rights, 11(Suppl 2), S5.

Stephen, C., \& Daibes, I. (2010). Defining features of the practice of global health research: An examination of 14 global health research teams. Global Health Action, 3, 5188.

The Association of Faculties of Medicine of Canada (2010). The future of medical education in Canada: A collective vision for MD Education. Available at www.afmc.ca/fmec/pdf/collective_vision.pdf (pp. 54). Ottawa, ON, Canada.

van den Scott, L.-J. K. (2012). Science, Politics, and Identity in Northern Research Ethics Licensing. Journal of Empirical Research on Human Research Ethics: An International Journal, 7(1), 28-36.

Vermund, S., Sahasrabuddhe, V., Khedkar, S., Jia, Y., Etherington, C., \& Vergara, A. (2008). Building global health through a center-without-walls: the Vanderbilt Institute for Global Health. Academic Medicine, 83(2), 154-164.

World Health Organization. (2010). A systematic evidence review to support development of policy guidelines for improving health worker access to prevention, treatment, and care services for HIV and TB / prepared for the World Health Organization by Annalee Yassi, Lyndsay M O'Hara, Karen Lockhart, Justin LoChang, Jerry M Spiegel, December 2009. Available from: http://www.who.int/occupational_health/systematic_review_for_ treat_policy_final.pdf.

World Health Organization, International Labour Office, \& the Joint United Nations Programme on HIV/ AIDS (UNAIDS). (2010). Joint WHO-ILO-UNAIDS policy guidelines on improving health workers' access to HIV and tuberculosis prevention, treatment, care and support services. Switzerland: WHO. Available from: http://whqlibdoc.who.int/publications/2010/9789241500692_eng.pdfGeneva.

Yassi, A., Cabarcas, F., Fujii, R., Orrego, E., Silva, F., \& Spiegel, J. M. (2007). UBC's experience in building partnerships for development in Ecuador - 2. From the bottom up: Creating communities of learning and practice. Paper presented at the 11th UNESCO-APEID International Conference "Reinventing Higher Education: Toward Participatory and Sustainable Development", Bangkok, Thailand, December 12-14.

Yassi, A., Dharamsi, S., Spiegel, J. M., Rojas, A., Dean, E., \& Woollard, R. (2010). The good, the bad and the ugly of partnered research: Revisiting the sequestration thesis and the role of universities in promoting social justice. International Journal of Health Services, 40(3), 485-505.

Yassi, A., O’Hara, L., Lockhart, K., \& Spiegel, J. M. (2012). Workplace programmes for HIV and Tuberculosis: A systematic review to support development of international guidelines for the health workforce. AIDS care, l(19), iFirst. 